Research Paper

\title{
Antioxidative defense enzymes in placenta protect placenta and fetus in inherited thrombophilia from hydrogen peroxide
}

\author{
Jelena Bogdanovic Pristov, ${ }^{1}$ Ivan Spasojevic, ${ }^{1}$ Željko Mikovic, ${ }^{2}$ Vesna Mandic, ${ }^{2}$ Nikola Cerovic ${ }^{2}$ and Mihajlo Spasic ${ }^{3, *}$ \\ 'University of Belgrade; Institute for Multidisciplinary Research; Department of Biophysics; Belgrade, Serbia; ${ }^{2}$ Department of Pathological Pregnancy; Clinical Centre for Obstetrics \\ and Gynecology; Belgrade, Serbia; ${ }^{3}$ University of Belgrade; Institute for Biological Research; Department of Physiology; Belgrade, Serbia
}

Key words: oxidative stress, placenta, hydrogen peroxide, thrombophilia, antioxidative defense, catalase, glutathione

Our aim was to investigate the activities of antioxidative defense enzymes in the placenta, fetal blood and amnion fluid in inherited thrombophilia. Thrombophilia was associated with nearly threefold increase of activity $(\mathrm{p}<0.001)$ of the placental catalase $(81.1$ $\pm 20.6 \mathrm{U} / \mathrm{mg}$ of proteins in controls and $270.0 \pm 69.9 \mathrm{U} / \mathrm{mg}$ in thrombophilic subjects), glutathione (GSH) peroxidase (C: $20.2 \pm$ $10.1 \mathrm{U} / \mathrm{mg}$; T: $60.0 \pm 15.5 \mathrm{U} / \mathrm{mg}$ ), and GSH reductase (C: 28.9 $\pm 5.6 \mathrm{U} / \mathrm{mg} ; \mathrm{T}: 72.7 \pm 23.0 \mathrm{U} / \mathrm{mg}$ ). The placental activities of superoxide dismutating enzymes-MnSOD and CuZnSOD, did not differ in controls and thrombophilia. Likewise, the activities of catalase and SOD in the fetal blood, and the level of ascorbyl radical which represents a marker of oxidative status of amniotic fluid, were similar in controls and thrombophilic subjects. From this we concluded that in thrombophilia, placental tissue is exposed to $\mathrm{H}_{2} \mathrm{O}_{2}$-mediated oxidative stress, which could be initiated by pro-thrombic conditions in maternal blood. Increased activity of placental $\mathrm{H}_{2} \mathrm{O}_{2}$-removing enzymes protects fetus and mother during pregnancy, but may increase the risk of postpartum thrombosis.

\section{Introduction}

Inherited thrombophilia represents a condition that predisposes individuals to thrombosis and thromboembolism, particularly during pregnancy. ${ }^{1,2}$ Under pro-thrombotic conditions related with both thrombophilia and pregnancy, haemostatic response and microthrombi are generated, which could lead to ischemic conditions and mechanical stress in blood vessels and consequent generation of reactive oxygen species (ROS). ${ }^{3,4}$ Intricately associated with endothelium injury and coagulation is inflammation, under which increased activity of leukocytes results in oxidative burst. ${ }^{5} \mathrm{~A}$ cascade of events initiated by oxidative stress, leads to series of responses, such as vasoconstriction, membrane oxidation and further pro-coagulation, ${ }^{3}$ each of which includes further generation of ROS. ${ }^{5-8}$ Such overproduction of ROS during pregnancy can damage placenta and

*Correspondence to: Mihajlo B. Spasic; Institute for Biological Research; University of Belgrade; Bulevar Despota Stefana 142; Belgrade 11060 Serbia; Tel. +381.11.2078.396; Fax: +381.11.761.433; Email: spasa@ibiss.bg.ac.yu

Submitted: 12/01/08; Revised: 12/16/08; Accepted: 12/17/08

Previously published online as an Oxidative Medicine and Cellular Longevity E-publication: http://www.landesbioscience.com/journals/oximed/article/7705 affect the function of placental circulation. ${ }^{9}$ All the above implies a potential relation between pro-thrombotic conditions in pregnancy complicated by thrombophilia and oxidative stress which has not been previously clearly linked. Thus, the aim of this study was to assess the role of oxidative stress and to identify the most abundant reactive oxygen species in thrombophilia. We evaluated the activity of five major enzymes of antioxidative system (AOS): catalase, GSH peroxidase and reductase, $\mathrm{MnSOD}$ and $\mathrm{CuZnSOD}$ in placental tissue obtained after Caesarean delivery of nine individuals with thrombophilia and of ten control subjects. The origin of oxidative stress was investigated by evaluating the oxidative status of the fetal blood and amniotic fluid.

\section{Results}

Figure 1 shows activities of $\mathrm{H}_{2} \mathrm{O}_{2}$-scavenging (catalase, GSH peroxidase/reductase) and superoxide dismutating (MnSOD and CuZnSOD) enzymes in placental tissue. It can be observed that the $\mathrm{H}_{2} \mathrm{O}_{2}$-scavenging enzymes were roughly three times more active in placentas of thrombophilic mothers than in controls. On the other hand, SOD activity was not modified in thrombophilia.

Native electrophoresis with staining specific for catalase or SOD activity was used to support results presented in Figure 1. Figure 2 shows characteristic bands obtained from controls and thrombophilic placentas. Quantification of the enzymatic activity of individual enzyme isoforms, performed by zymograms, showed that the activity of catalase in the control group was 33\% of the activity of catalase determined in the thrombophilia group. The activity of $\mathrm{CuZnSOD}$ in the controls was $93 \%$ of its activity in thrombophilic individuals, while the MnSOD activity in thrombophilic subjects was $97 \%$ of the MnSOD activity in controls. This fully corresponds to the spectrophotometric results.

Catalase and SOD activities in the fetal blood were evaluated in order to determine whether increased level of $\mathrm{H}_{2} \mathrm{O}_{2}$ in placental tissue originates from fetal circulation. Enzymes activity were similar in the blood obtained from the cord of newborns delivered after normal pregnancies and pregnancies associated with thrombophilia (Catalase: $16001 \pm 3333 \mathrm{U} / \mathrm{g}$ of $\mathrm{Hb}$ in controls, $15311 \pm 2284 \mathrm{U} / \mathrm{g}$ $\mathrm{Hb}$ in thrombophilia; Total SOD: $6952 \pm 1101 \mathrm{U} / \mathrm{g} \mathrm{Hb}$ in controls, $6806 \pm 499 \mathrm{U} / \mathrm{g} \mathrm{Hb}$ in thrombophilia; $\mathrm{p}>0.05)$.

Relative level of ascorbyl radical in amniotic fluid was evaluated using EPR spectroscopy, in order to determine oxidative status of 
the fluid. ${ }^{10,11}$ Figure 3 shows characteristic spectra acquired from amniotic fluid of controls and pregnancies complicated by thrombophilia. Calculated amplitudes of EPR signal of ascorbyl radical did not differ (data not shown), demonstrating that the oxidative status of the amniotic fluid remains unchanged in thrombophilia.

\section{Discussion}

The findings demonstrate that oxidative pressure is exerted on placenta in thrombophilia. Significant increase of activities of $\mathrm{H}_{2} \mathrm{O}_{2}$-removing enzymes (catalase and GSH peroxidase) shows that the major reactive specie affecting the placental tissue is hydrogen peroxide. It seems to be of extra-placental origin, since SOD activity as the principal source of $\mathrm{H}_{2} \mathrm{O}_{2}$ in tissues, remains unchanged in thrombophilia. Hydrogen peroxide can pass membranes of placental cells and therefore could be supplemented via fetal or maternal blood or by amniotic fluid. However, AOS activity in the fetal blood and oxidative status of amniotic fluid were not increased in thrombophilia. So, $\mathrm{H}_{2} \mathrm{O}_{2}$ is most likely distributed to placental tissue from mother's blood and endothelium. There it can be generated in the chain-reaction initiated by pro-thrombic conditions related with thrombophilia. Under such conditions haemostatic response and micro-thrombi can lead to ischemia, vessel injury and to related increased generation of ROS. ${ }^{3,4}$ Cascade of events can be activated, leading to vasoconstriction, leukocyte adhesion and infiltration, membrane oxidation and further pro-coagulation. ${ }^{3}$ Each of these particular processes includes further generation of ROS. ${ }^{5-8}$ We hypothesize that oxidative burst generated by such chain-reaction, could lead to increased level of $\mathrm{H}_{2} \mathrm{O}_{2}$ in thrombophilic placentas.

Hydrogen peroxide as a membrane-permeable molecule could initiate a variety of responses. At high concentrations, $\mathrm{H}_{2} \mathrm{O}_{2}$ can provoke oxidative damage and affect various signaling pathways, ${ }^{12}$ which could lead to dysfunction of placental cells. ${ }^{9}$ Placental blood flow, which is essential for the normal function of placenta and is critical for fetal development, could be also affected, since $\mathrm{H}_{2} \mathrm{O}_{2}$ is known to modulate vessel function in a complex way, acting as both a vasoconstrictor and a vasodilator. ${ }^{13,14}$ As a vasoconstrictor, $\mathrm{H}_{2} \mathrm{O}_{2}$ could provoke reduced placental perfusion. The constancy of the placental perfusion may be even more important factor than the absolute rate of blood flow, as biphasic effect of $\mathrm{H}_{2} \mathrm{O}_{2}$ could lead to ischemia/reperfusion oxidative injury. ${ }^{14}$ Depending on the severity and frequency of such assaults, the outcome might range from mild oxidative stress to severe damage of the placental tissue. ${ }^{15}$ On the other hand, increased level of $\mathrm{H}_{2} \mathrm{O}_{2}$ can not provoke uterine contractions in thrombophilic mothers, since $\mathrm{H}_{2} \mathrm{O}_{2}$ shows only relaxing effects on myometrial smooth muscle (our unpublished observations on rat uteri), which is substantially different than any other smooth muscle. ${ }^{16}$

The findings confirm the previously established good correlation between the oxidative state of the mother and the neonate. ${ }^{17}$ As $\mathrm{H}_{2} \mathrm{O}_{2}$ can provoke such vast range of pathophysiological changes, placenta ought to defend itself in thrombophilia by AOS activation. If the protection fails, thrombophilia result into other pregnancy complications, ${ }^{18}$ and even miscarriage represents a potential outcome. ${ }^{19-21}$ Enzymes of AOS present in placenta may also partially protect maternal blood from excessive amounts of $\mathrm{H}_{2} \mathrm{O}_{2}$. If such protection fails during pregnancy, pro-thrombotic condition may lead to thrombosis. Until modern obstetrics made an impact, the risk of thrombosis was reaching peak postpartum, immediately

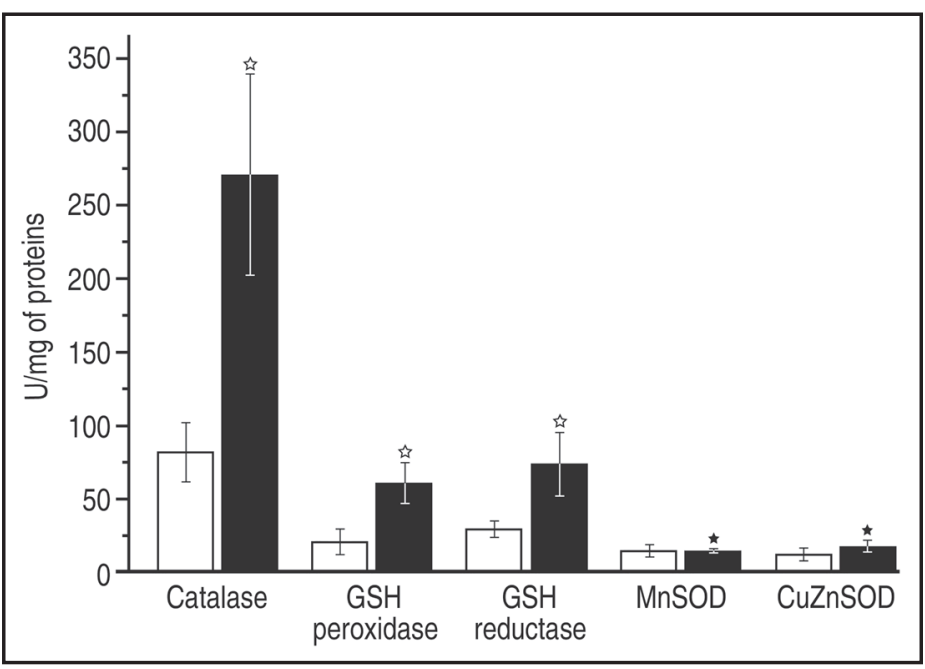

Figure 1. Activity of AOS enzymes in the placental tissue. Results are presented as means \pm S.D. Controls-white columns; Thrombophilia-black columns. White star: statistically significant $(p<0.001)$; Black star: statistically insignificant $(p>0.05)$.



Figure 2. Isoenzyme pattern of the catalase enzyme on polyacrylamide gels after native electrophoresis and of the activity of SOD in polyacrylamide gels after isoelectrofocusing of placental tissue samples.

after delivery. ${ }^{22,23}$ We propose that at the delivery, after placenta is discarded, protection of maternal blood is instantaneously diminished. While the generation of $\mathrm{H}_{2} \mathrm{O}_{2}$ should continue, exerting increased oxidative pressure on maternal blood. Such pro-oxidative conditions in maternal blood could promote development of thrombosis postpartum.

AOS, represented by functionally connected set of enzymes and low molecular mass components, have physiological role to to maintain cellular redox state and to neutralize and/or suppress oxidative damages induced by ROS. Abnormal activity of AOS or some of 


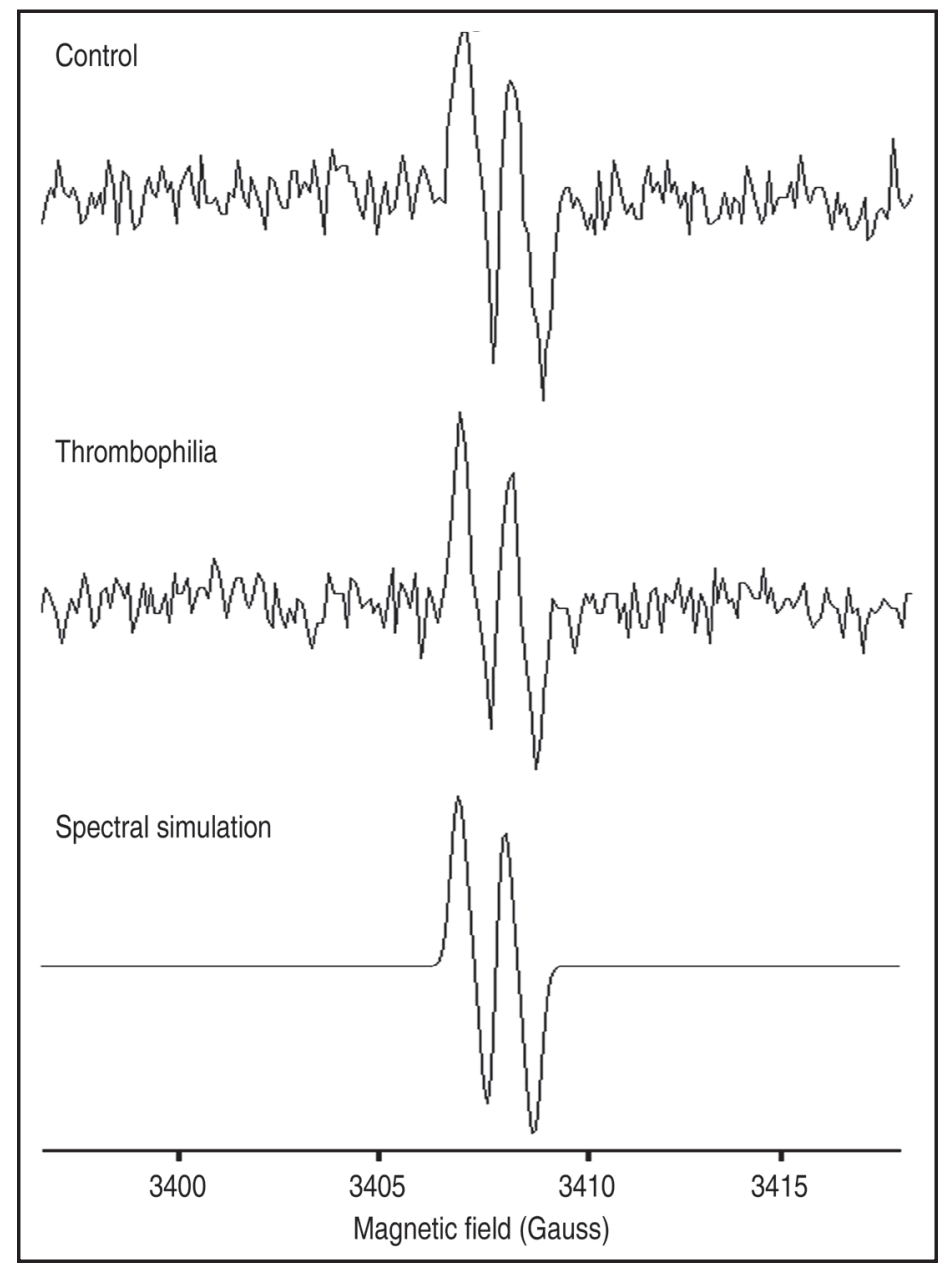

Figure 3. Characteristic EPR spectra of the ascorbyl radical in amniotic fluid of normal and thrombophilic pregnancies. Bottom panel shows spectral simulation that was used as a reference for identification of this radical in amniotic fluid.

\section{Table 1 Baseline characteristics}

\begin{tabular}{lccc}
\hline & $\begin{array}{c}\text { Control } \\
(\mathbf{n}=10)\end{array}$ & $\begin{array}{c}\text { Thrombophilia } \\
(\mathbf{n}=\mathbf{9})\end{array}$ & p value \\
Maternal age (years) & $26.9 \pm 3.9$ & $29.3 \pm 3.8$ & $>0.05$ \\
Smokers (n (\%)) & $2(20)$ & $1(9)$ & $>0.05$ \\
Gestational age (weeks) & $38 \pm 2$ & $32 \pm 3$ & $>0.05$ \\
Neonate weight (g) & $3457 \pm 805$ & $1388 \pm 501$ & $<0.05$ \\
\hline
\end{tabular}

its component(s) represent a straightforward proof of pro-oxidative conditions in any tissue. On the other hand, oxidative status of body fluids (e.g., extracellular fluid), which are poor in AOS enzymes, can be determined by the level of ascorbyl radical. ${ }^{11}$ Ascorbyl radical, which is generated via radical scavenging by ascorbate, is relatively stabile and readily detected using EPR spectroscopy. ${ }^{10,11}$ To the best of our knowledge, this is the first time that such approach was used on amniotic fluid.

As there are extensive evidences of the essential role of reactive species in the development of various disorders, ${ }^{12}$ among which are pregnancy complications, ${ }^{17}$ the application of methods that are able to determine oxidative status of tissues and fluids becomes more clinically relevant. Screening of the level of ascorbyl radical in amniotic fluid during pregnancy, or AOS activity in placental tissue or fetal blood postpartum could provide information that could indicate development of some disorder, such as thrombophilia. Based on the obtained data, decision should be made whether to involve antioxidant therapy in order to prevent fetal injury or postpartum complications.

\section{Patients and Methods}

Patients. Our study included nine pregnancies with inherited thrombophilia (study group) and ten normal pregnancies (control group). The demographic characteristics of the groups are presented in Table 1.

Inherited thrombophilias were detected by measuring the biological activity of antithrombin and evaluating the presence of specific mutations-factor V Leiden and factor II 20210A. ${ }^{19}$ Among nine women in the study group: one had antithrombin deficiency, five resistance to activated protein $\mathrm{C}$ with factor $\mathrm{V}$ Leiden mutation and three factor II 20210A mutation. In all the patients the diagnosis of inherited thrombophilia was made only on the basis of pregnancy complications since none of them had history of thrombosis. Five patients were diagnosed before the index pregnancy, while the other four were diagnosed during the index pregnancy. All of them received therapeutic doses of low molecular weight heparin; those diagnosed before pregnancy from the beginning of the pregnancy and those diagnosed later immediately after the detection of thrombophilia. Anticoagulant therapy was continued during the postpartum period in all patients with thrombophilia. All patients (control and study group) received multivitamin supplement that contained $100 \mathrm{mg}$ of vitamin $\mathrm{C}$ each day.

All of the nineteen patients were delivered by elective Cesarean section. In the study group Cesarean section had been done due to maternal complications, fetal distress or as iterative, while in the control group it had been as second iterative. All of the neonates were live-born. Intrauterine growth restriction, defined as estimated fetal and neonatal birth weight beyond $10^{\text {th }}$ percentile for the gestational age, has been detected in five of nine cases with thrombophilia.

Institutional approval for the study was granted by The Clinics Ethics Committee in accordance with internationally accepted ethical standards (The Helsinki Declaration of 1964, as revised in 1975, 1983 and 1989), and each patient had signed the informed consent form.

Samples. Placentas were obtained immediately after delivery. Placental tissue pieces (six per placenta) were dissected from different cotyledons midway between the chorionic and basal plates. ${ }^{24}$ Six samples per each placenta were taken free of visible infarction, calcification or hematoma. The tissue samples were immediately washed with ice-cold saline to remove blood. Cord blood was taken immediately after the delivery in commercial containers filled with citrate. Amniotic fluid of control patients was obtained at delivery. Specimens of placenta and amniotic fluid have been snap-frozen in liquid nitrogen and stored at $-85^{\circ} \mathrm{C}$. Citratetreated blood samples were centrifuged at 2,000 $\mathrm{xg}$ for $15 \mathrm{~min}$ at $4^{\circ} \mathrm{C}$, and the separated erythrocytes were washed three times with $0.9 \% \mathrm{NaCl}$ and than frozen. 
Spectrophotometric assays. Frozen villous tissues were thawed on ice and $1 \mathrm{~g}$ of wet fragments was homogenized in 10 volumes of ice-cold homogenizing buffer $(50 \mathrm{mM}$ Tris- $\mathrm{HCl}, 250 \mathrm{mM}$ sucrose, $1 \mathrm{mM}$ EDTA, $\mathrm{pH}$ 7.4). The homogenates were centrifuged at 100,000 $\mathrm{xg}$ at $4^{\circ} \mathrm{C}$ for $90 \mathrm{~min}$. Protein contents in supernatants were determined using the method of Lowry. Supernatants were frozen in liquid nitrogen and stored at $-85^{\circ} \mathrm{C}$. Erythrocytes from fetal blood $(0.5 \mathrm{ml})$ were lysed by adding $3 \mathrm{ml}$ of ice-cold distilled water. Hemoglobin $\mathrm{Hb})$ concentration was measured by the Drabkin method.

SOD activity was measured according to the previously described method. ${ }^{25}$ Interference from hemoglobin was eliminated by precipitation prior to the assay using ethanol/chloroform $(1: 1, \mathrm{v} / \mathrm{v})$ that was followed by centrifugation at 3,000 $\mathrm{xg}$ for five minutes at $4^{\circ} \mathrm{C}$. MnSOD activity was determined in the presence of $5 \mathrm{mM} \mathrm{KCN}$ that inhibits the activity of CuZnSOD. Previously described methods were used to determine activities of catalase, ${ }^{26} \mathrm{GSH}$ peroxidase ${ }^{27}$ and GSH reductase. ${ }^{28}$ The activity of the enzymes in the placental tissue was expresses as $\mathrm{U} / \mathrm{mg}$ of proteins, while the activity of catalase and $\mathrm{SOD}$ in blood was presented as $\mathrm{U} / \mathrm{g}$ of $\mathrm{Hb}$.

Electrophoresis. Native polyacrylamide gel electrophoresis was carried out under non-denaturing conditions in gels containing $8 \%$ polyacrylamide with a $4 \%$ stacking gel. A constant current of $25 \mathrm{~mA}$ per gel was applied. Electrophoresis buffers and gels were prepared as described previously, ${ }^{29}$ with the exception that SDS was excluded. Catalase was stained as previously described. ${ }^{30}$

In order to determine the SOD activity, non-equilibrated isoelectric focusing was performed horizontally in the LKB 2117 Multiphor II system, using $0.5 \mathrm{~mm}$ thick polyacrylamide gels ( $5 \% \mathrm{~T}, 3 \% \mathrm{C})$ that contained 4\% 3.5-10.0 ampholites. Gels were solidified with $50 \mu \mathrm{L}$ of $10 \%$ ammonium persulfate and $7 \mu \mathrm{L}$ of TEMED per 15 $\mathrm{mL}$ of gel solution. Gels were run at $4^{\circ} \mathrm{C}$ with the constant power of $0.25 \mathrm{~W} / \mathrm{cm}$ width of gel, with limiting voltage of $1,000 \mathrm{~V}$ for two hours. SOD isoenzymes were detected on the gels by staining for 20 minutes in the dark in $20 \mathrm{~mL} 100 \mathrm{mM}$ sodium phosphate buffer $\mathrm{pH}$ 7.8 with $4 \mathrm{mg}$ of nitrobluetetrazolium, $0.6 \mathrm{mg}$ of riboflavine, $2 \mu \mathrm{L}$ of TEMED and $40 \mu \mathrm{L}$ of $0.25 \mathrm{M}$ NaEDTA. After that, the gels were briefly rinsed with distilled water and illuminated for 15 minutes. Quantification of enzyme activity of individual isoforms was performed from zymograms, using the Image Master TotalLab v1.11 (Amersham Pharmacia Biotech, Piscataway; NJ USA) program. Enzyme quantifications were all done in quadruplicate.

EPR study of oxidative status of amniotic fluid. Electron paramagnetic resonance (EPR) measurements of the level of ascorbyl radical in amniotic fluid were performed in order to determine its oxidative status. ${ }^{10,11}$ Aliquots of the amniotic fluids were drawn into quartz capillaries. EPR spectra were recorded at room temperature using a Varian E104-A EPR spectrometer operating at X-band $(9.51 \mathrm{GHz})$, with the following settings: modulation amplitude, $2 \mathrm{G}$; modulation frequency, $100 \mathrm{kHz}$; and microwave power of $10 \mathrm{~mW}$. Spectra were recorded using EW software (Scientific Software; Bloomington, IL USA). Computer simulation of EPR spectrum of ascorbyl radical was performed using the WINEPR SimFonia computer program (Bruker Analytische Messtechnik GmbH; Rheinstetten, Germany) and spectral parameter $a^{H}=2.3$. Simulation was used to identify signal and to calculate amplitudes.

All the chemicals used in this study were purchased from SigmaAldrich (St. Louis, MO, USA) and Merck (Darmstadt, Germany).
Statistical analysis. Measurements were performed on six separate placenta samples and one sample of amniotic fluid and fetal blood obtained from each patient. Statistical differences were evaluated by means of the non-parametric two-tailed Mann-Whitney test using Statistica 6.0 (StatSoft Inc., Tulsa, OK, USA). Results are presented as means \pm S.D. (standard deviation) and were taken to be statistically different if $\mathrm{p}<0.05$.

\section{Acknowledgements}

This work was supported by the Grants from the Ministry of Science of Republic of Serbia, 143016, 143043 and 143034. We declare no conflicts of interest (financial or otherwise).

\section{References}

1. Sarig G, Brenner B. Coagulation, inflammation and pregnancy complications. Lancet 2004; 363:96-7.

2. Walker ID, Greaves M, Preston FE. Investigation and management of herritable thrombophilia. Br J Haematol 2001; 114:512-28.

3. Crimi E, Ignarro LJ, Napoli C. Microcirculation and oxidative stress. Free Rad Res 2007; 41:1364-75.

4. Laude I, Rongieres-Bertrand C, Boyer-Neumann C, Wolf M, Mairovitz V, Hugel B, et al. Circulating procoagulant microparticles in women with unexplained pregnancy loss: A new insight. Thrombosis and Haemostasis 2001; 85:18-21.

5. Prescott SM, McIntyre TM, Zimmerman GA, Stafforini DM. Molecular events in acute inflammation. Arterioscler Thromb Vasc Biol 2002; 22:727-33.

6. Krötz F, Sohn HY, Pohl U. Reactive oxygen species: Players in the platelet game. Arterioscler Thromb Vasc Biol 2004; 24:1988-96.

7. Rowe GT, Eaton LR, Hess ML. Neutrophil-derived, active oxygen species-mediated cardiovascular dysfunction. J Vol Cell Cardiol 1984; 16:1075-9.

8. Sundaresan M, Yu ZX, Ferrans VJ, Irani K, Finkel T. Requirement for generation of $\mathrm{H}_{2} \mathrm{O}_{2}$ for platelet-derived growth factor signal transduction. Science 1995; 270:296-9.

9. Jauniaux E, Poston L, Burton GJ. Placental-related diseases of pregnancy: Involvement of oxidative stress and implications in human evolution. Hum Reprod Update 2006; 12:747-55.

10. Buettner GR, Jurkiewicz BA. Ascorbate free radical as a marker of oxidative stress: An EPR study. Free Rad Biol Med 1993; 14:49-55.

11. Chen Q, Espey MG, Sun AY, Lee JH, Krishna MC, Shacter E, et al. Ascorbate in pharmacologic concentrations selectively generates ascorbate radical and hydrogen peroxide in extracellular fluid in vivo. Proc Natl Acad Sci USA 2007; 104:8749-54.

12. Dröge W. Free radicals in the physiological control of cell function. Physiol Rev 2002; 82:47-95.

13. Gao YJ, Hirota S, Zhang DW, Janssen LJ, Lee RMKW. Mechanisms of hydrogen-peroxideinduced biphasic response in rat mesenteric artery. Br J Pharm 2003; 138:1085-92.

14. Lucchesi PA, Belmadani S, Matrougui K. Hydrogen peroxide acts as both vasodilator and vasoconstrictor in the control of perfused mouse mesenteric resistance arteries. J Hypertens 2005; $23: 571-9$

15. Hung TH, Skepper JN, Burton GJ. In vitro ischemia-reperfusion injury in term human placenta as a model for oxidative stress in pathological pregnancies. Am J Pathol 2001; 159:1031-43.

16. Buxton ILO. Regulation of uterine function: A biochemical concordium in the regulation of smooth muscle relaxation. Mol Pharmacol 2004; 65:1051-9.

17. Aeguelles S, Machado MJ, Ayala A, Machado A, Hervias B. Correlation between circulating biomarkers of oxidative stress of maternal and umbilical cord blood at birth. Free Rad Res 2006; 40:565-70.

18. Kujovich JL. Thrombophilia and pregnancy complications. Am J Obstet Gynecol 2004; 191:412-24.

19. Alonso A, Soto I, Urgellés MF, Corte JR, Rodríguez MJ, Pinto CR. Acquired and inherited thrombophilia in women with unexplained fetal losses. Am J Obstet Gynecol 2002; 187:1337-42.

20. Greer IA. Thrombophilia: Implications for pregnancy outcome. Thromb Res 2003; 109:73-81.

21. Rey E, Kahn SR, David M, Shrier I. Thrombophilic disorders and fetal loss: A metaanalysis. Lancet 2003; 361:901-8.

22. Toglia MR, Nolan TE. Venous thromboembolism during pregnancy: A current review of diagnosis and management. Obstet Gynecol Surv 1997; 52:60-72.

23. Toglia MR, Weg JG. Venous thromboembolism during pregnancy. N Engl J Med 1996; 335:108-14.

24. Hempstock J, Bao Y-P, Bar-Issaca M, Segarena N, Watsona AL, Charnock-Jonesb DS, et al. Intralobular differences in antioxidant enzyme expression and activity reflect the pattern of maternal arterial blood flow within the human placenta. Placenta 2003; 24:517-23.

25. McCord JM, Fridovich I. The reduction of cytochrome $\mathrm{C}$ by milk xantine oxidase. J Biol Chem 1968; 243:5753-60.

26. Claiborne A, ed. Handbook of Methods for Oxygen Radical Research. Boca Raton, FL: CRC Press Inc 1984. 
27. Paglia DE, Valentine NW. Studies on the quantitative and qualitative characterization of erythrocyte glutathione peroxidase. J Lab Clin Med 1967; 70:74-7.

28. Glatzle D, Vuilleumier JP, Weber F, Decker K. Glutathione reductase test with whole blood: A convenient procedure for the assessment of the riboflavin status in humans. Experientia 1974; 30:665-8.

29. Laemmli UK. Cleavage of structural proteins during assembly of head of bacteriophage T4. Nature 1970; 227:680-5.

30. Woodbury W, Spenser AK, Stahmann MA. An improved procedure using ferricyanide for detecting catalase isoenzymes. Analyt Biochem 1971; 41:301-5. 


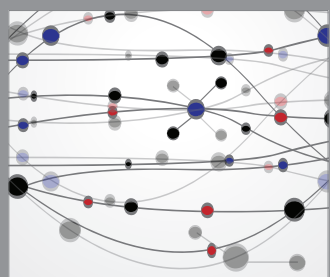

The Scientific World Journal
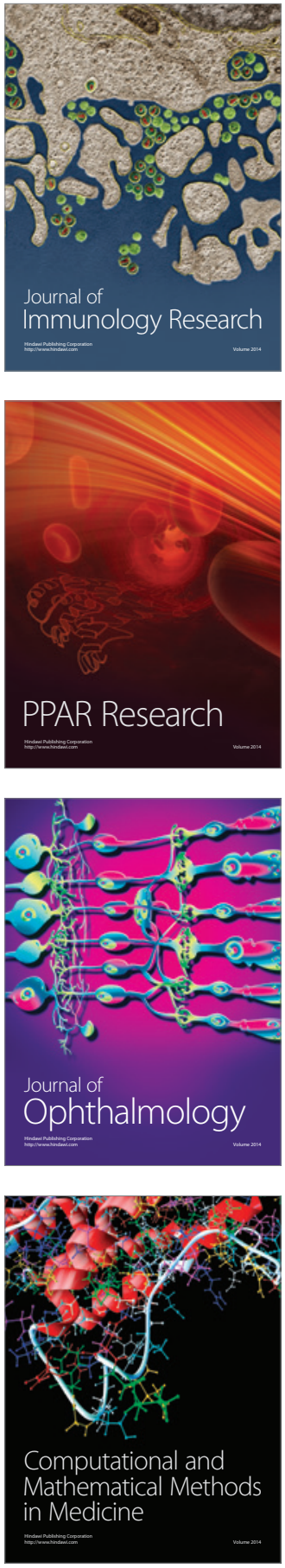

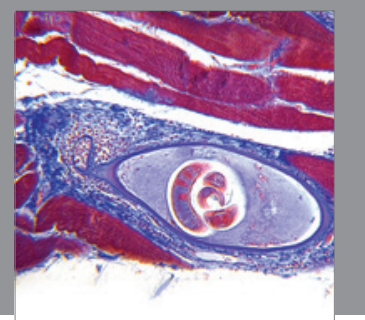

Gastroenterology

Research and Practice
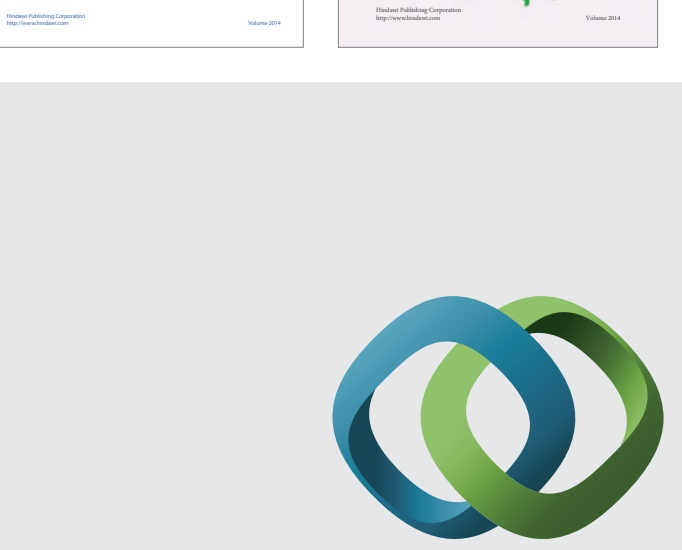

\section{Hindawi}

Submit your manuscripts at

http://www.hindawi.com
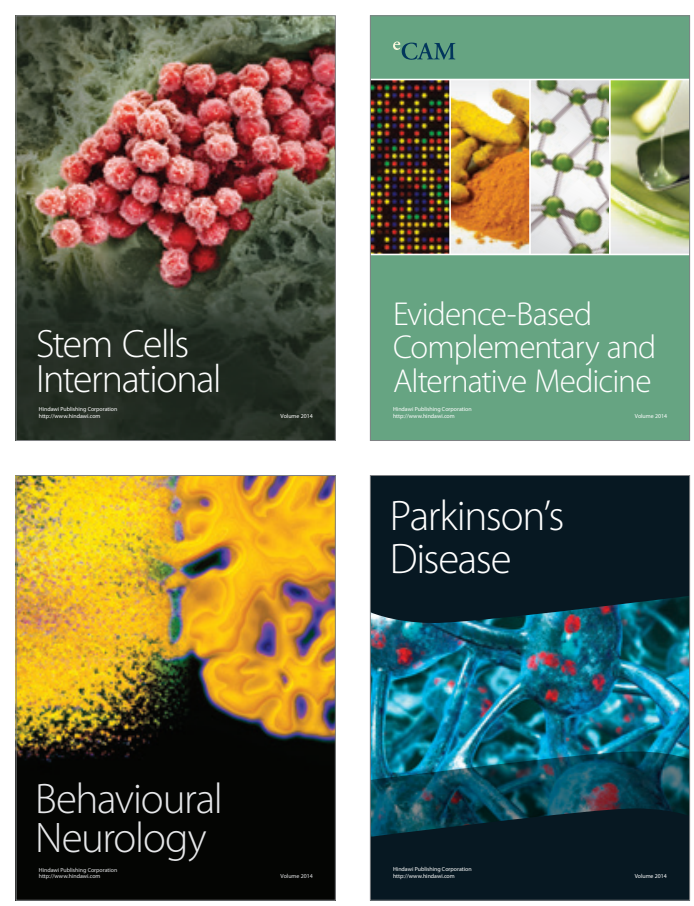

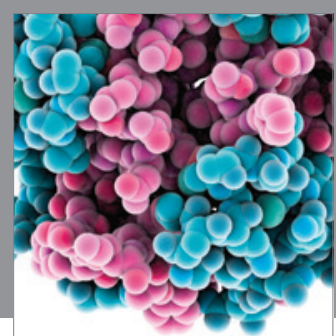

Journal of
Diabetes Research

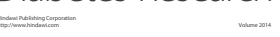

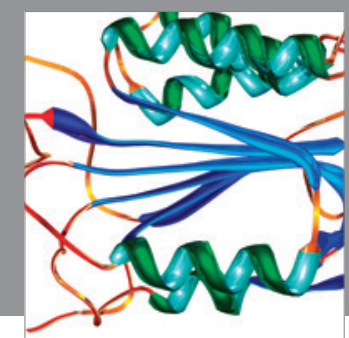

Disease Markers
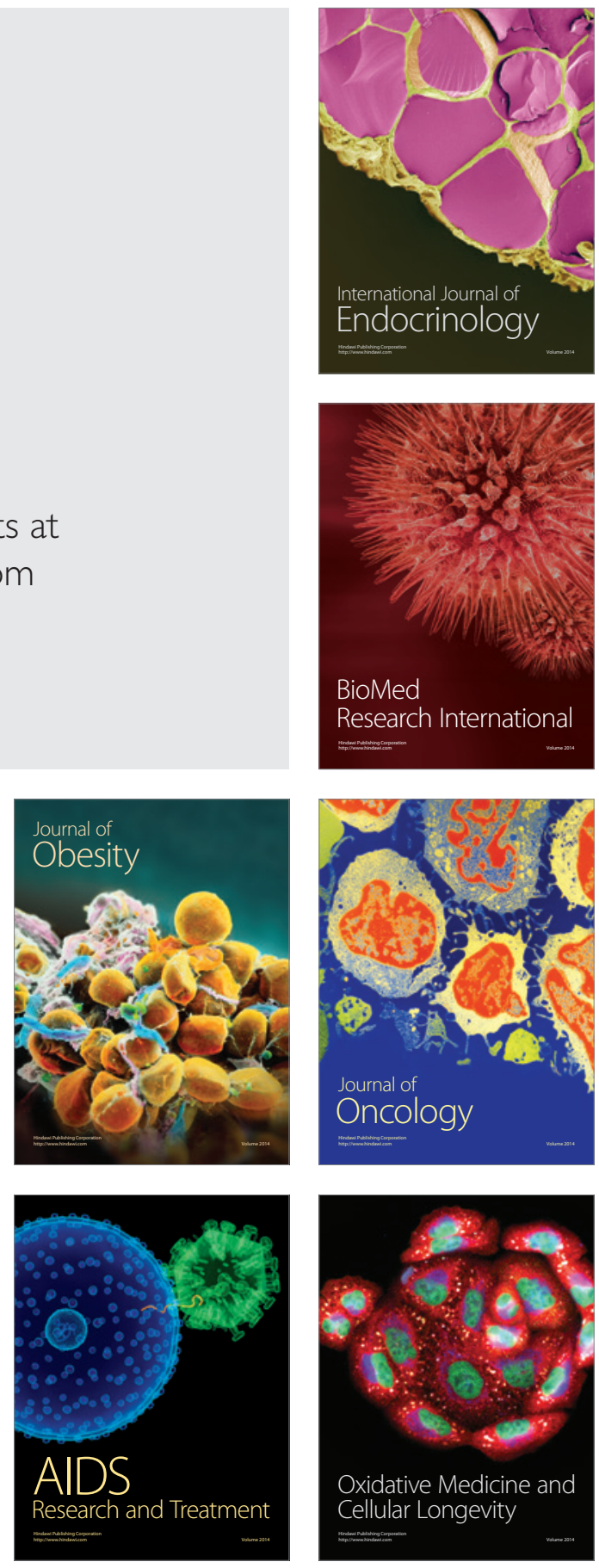